\title{
Pumping Up the Base: Deployment of Strong Emotion and Simple Language in Presidential Nomination Acceptance Speeches
}

\author{
Cynthia Whissell * \\ Psychology Department, Laurentian University, Sudbury, ON, Canada
}

Background and Method: This research examines the nomination acceptance speeches of US presidential candidates from Republican and Democratic parties in the post-WWII mass communication era (1948-2020, 38 speeches). Variables studied are the emotional tone of the speeches, their abstractness, their Grade Level, their employment of personal pronouns and their mentions of "America". Speeches were scored with the Dictionary of Affect in Language (a sentiment analysis tool).

Predictions: On the basis of functionalist theories of political discourse, it was predicted

OPEN ACCESS

Edited by: Daniel Broudy,

Okinawa Christian University, Japan

Reviewed by:

Karen Sebold,

University of Arkansas, United States Matthew Eshbaugh-Soha, University of North Texas, United States

*Correspondence:

Cynthia Whissell cwhissel/@/aurentian.ca

Specialty section: This article was submitted to Political Communication and Society, a section of the journal Frontiers in Communication

Received: 23 June 2021 Accepted: 10 September 2021

Published: 17 November 2021

\section{Citation:}

Whissell C (2021) Pumping Up the Base: Deployment of Strong Emotion and Simple Language in Presidential Nomination Acceptance Speeches.

Front. Commun. 6:729751. doi: $10.3389 / f c o m m .2021 .729751$ that the speeches would have a pleasant and active or celebratory emotional tone. Based on related research that focused on the effects of mass distribution on presidential communications, it was predicted that the speeches would increase in pleasantness, arousal and linguistic simplicity across years.

Results: As predicted, speeches were pleasant and active in tone. Across years, speeches became significantly more arousing, less abstract, simpler, and longer. When individual speeches were divided into five equal portions, a strong significant quadratic trend was observed for pleasantness, which started high at the beginning of a speech, fell in the center, and rose again at the end.

Conclusions: Presidential nomination acceptance speeches are emotionally pleasant and active and linguistically simple (Grade 8 level). Between 1948 and 2020, they remained pleasant, and became more active and simpler. In service of their aim to "pump up the base" individual speeches began on a pleasant, nationalistic and personal note, encompassed duller and more impersonal material in their centers, and became positive again at the end.

Keywords: presidential nomination contests, emotion, language complexity, functionality, mass distribution

\section{INTRODUCTION}

Functionalist theories of rhetoric (Benoit, 1999, Benoit, 2014; Benoit et al., 1998, Benoit et al., 2004) posit that political speeches, including the presidential nomination acceptance speeches of modern candidates, are instrumental in nature. Form follows function and speeches are deliberately structured to promote desired outcomes. The emotional tone of speeches is part of the arsenal deployed with intent to influence an audience and accumulate votes. Nomination acceptance 
speeches are celebratory, coming as they do at the end of a long selection process; they also serve to unify the party, to provide a climactic moment for the convention, and to outline the platform on which the candidate will run (Benoit, 1999). Attack and defense are two of the main functions of political speeches (Benoit et al., 1998), with acclaim, which is key to acceptance speeches, being a third. Whissell (2012) reported on the thrust and parry nature of interchanges in the Canadian parliament's Question Period: questioners from opposition parties tended to use more aggressive language then responders who spoke for the ruling party in attempts to deflect attacks. Benoit (1999) noted that nomination acceptance speeches tended to focus on acclaim rather than attack, in a ratio of roughly three acclaims to each attack. Such findings lead to the expectation that presidential nomination acceptance speeches will have a positive and active emotional tone that promotes celebration and unity and reflects the acclamatory mood of the speeches.

This research examines presidential nomination acceptance speeches with the help of a sentiment analysis tool, the Dictionary of Affect in Language (Whissell, 2009). Such tools quantify the language employed in communications in terms of its underlying emotional tone (Young and Soroka, 2012). The Dictionary has been applied to the study of presidential inaugural addresses (Whissell and Sigelman, 2001) and presidential radio communications (Sigelman and Whissell, 2002), as well as other types of political communications (Sigelman, 2002; Whissell, 2012). In its present form (Whissell, 2009), the Dictionary provides scores for the pleasantness or positivity of a text, its activation or arousal, and the extent to which the words in the text promote strong visual imagery. Scoring is accomplished on a word by word basis. The presence of extremely pleasant words (e.g., hope, happy, win, wisdom, comfort, and successes) adds to the overall positivity of a speech while the presence of unpleasant words (e.g., sick, alone, argued, attacked, failure, and turmoil) decreases it. A speech containing many active words (e.g., adventure, energetic, discovery, nightmare, weapons, and violently) has a more arousing tone while one containing passive words (e.g., solemn, senior, slowed, ending, ignorance, and humble) is calmer and quieter in tone. Finally, an acceptance speech containing many words that are easily envisioned (e.g., dollars, children, people, guns, banks, and newspaper) would score higher on imagery or concreteness, while one which contained words that do not easily promote mental pictures (e.g., conduct, preservation, opportunity, finally, justify, and dignity) would be abstract. The examples provided here are extreme words from the nomination acceptance speeches studied. Imagery, the third dimension of the Dictionary of Affect, is not, strictly speaking, an affective dimension. It is a cognitive one (Vecchi, 2019). Images associated with words, (and therefore speeches) can make them easier to remember (Marre et al., 2021). When emotions or abstract concepts are being discussed, for example when people describe their feelings or when they debate the meaning of "justice", the words employed tend to be abstract and difficult to image. They do not easily stimulate mental pictures representing their meanings. This does not imply that the meaning of these words is unclear, but rather that the words are associated with non-pictorial concepts.

The first prediction of the research (P1), is that presidential nomination acceptance speeches will have a positive, active and abstract tone. This prediction will be tested by comparing the three scale means from Dictionary of Affect scoring of the speeches to normative values for a large sample of everyday English. It is specifically expected that pleasantness and activation values for presidential nomination acceptance speeches will be above the normative value while imagery will be below it.

Whissell and Sigelman (2001) pointed out that presidential inaugural addresses changed across time, as a function of their expected audience, with speeches becoming simpler and more emotional as the audience grew larger, thanks to developments in mass communication. On this basis, it was predicted (P2) that nomination acceptance speeches would follow the same pattern, becoming more pleasant and active, and also simpler, across time. The prediction of simplicity has two parts: it was expected that speeches would become more concrete, and therefore have higher scores for imagery across time, and it was predicted that the Grade Level (Flesch-Kincaid Grade Level) of the speeches would fall across time. Correlations of yearly mean values with year itself were employed to test this second set of predictions.

Two additional types of measures were added to the research, but these were treated in an exploratory manner and were not associated with specific predictions. The 1996 film comedy "My Fellow Americans" takes its name from a phrase commonly associated with the opening of political addresses, where it does, in fact, frequently appear (Waldeman, 2010). This phrase and its variants ("My fellow Republicans"; "My fellow Democrats") appear repeatedly in presidential nomination acceptance speeches. The pronoun "my", and the word "fellow" join the audience to the speaker. The use of pronouns such as "my" in political speeches was examined by a variety of researchers (e.g., Bull and Fetzer, 2006; Savoy, 2010; Vertommen, 2013; Putri and Kurniawan, 2015). Four additional measures of the research were associated with the frequency of use of individual words: first-person pronouns (e.g., I, we), secondperson pronouns (e.g., you, your), third person pronouns (e.g., he, she, and they), and the use of the word "America" in its various forms. The final type of measure addressed within-speech structure for the addresses. Several researchers who analyzed presidential nomination speeches (e.g., Miller and Styles, 1986; Benoit, 1999; Deason and Gonzales, 2012) have examined them as a unit. In this research is was decided to also examine the speeches in five parts or portions, with each portion of a speech containing a roughly equal number of words. If speeches are structured to a purpose, it is likely that their beginning, middle, and end would serve different functions and yield different values for the variables under study.

\section{METHODS}

Presidential nomination acceptance speeches were downloaded in March and April, 2021, from the American Presidency Project of the University of California at Santa Barbara. Most, but not all 
acceptance speeches were given at conventions. The most recent exception is Joe Biden's acceptance speech which was delivered at a convention but remotely, due to COVID-19 pandemic restrictions. Comments by the audience were removed from all speeches. Each speech was then scored by an SPSS program that compared every word in it to the Dictionary of Affect and imported scores for any matched words into a data file. The 38 speeches contained a total of 157,956 words, $93 \%$ of which had scores associated with them for pleasantness, activation, and imagery. A simple matching-and-counting analysis for string variables in SPSS was employed to identify the relative frequency of first-person, second-person, and third person personal pronouns, and the use of America-words (America, American, and Americans...). Speeches were divided into five equal parts or portions on the basis of the length of each speech. Speeches were scored using the readability statistics available in Word ${ }^{\circledR}$ under the Spelling and Grammar function in Review. This function produces a Flesch-Kincaid Grade Level, which reflects the grade of readers for whom the text would be appropriately complex (Stockmeyer, 2009). Grade Levels of 9-12 would be suitable for high school students, and Grade Levels of 13-16 for university students. A Grade Level of 18 would suggest that the text was appropriate for graduate students. The Grade Level for this paragraph is 13.6 .

Although the Dictionary has a high scoring rate (typically $90 \%$, $93 \%$ in this research, with a standard deviation across speeches of $1 \%)$, there are still issues associated with its use. One such issue is the possible multiple meanings of single words and another the very high natural variability of language. The word "read" for example, is used in many different ways. It represents several tenses of the same original verb, and it can also serve as a noun (“That was a good read!"). The Dictionary of Affect does not report multiple meanings, as there is only one set of ratings in it associated with the word "read" which is very pleasant, quite active, and very easy to image. It is assumed that each of the raters who originally provided the dimensional scores for the Dictionary was thinking of one possible meaning of "read", but not necessarily of the same meaning. The scores in the Dictionary therefore represent "What people think of when confronted with a word," and do not differentiate between possible multiple meanings. The shortcoming of ambiguous meanings is characteristic of any dictionary-scored system of language analysis. In this research, thousands of words were scored for the speech of every candidate, and matching rates were uniform, so it is unlikely that multiple meanings would differentially affect the speeches of different candidates. As well, a few confusing words in a large sample can hardly skew the result for the whole sample that contains thousands of scored words. Rudkowsky and co-authors (Rudkowsky and Haselmeyer, 2018), refer to dictionary- or lexicon-based methods of sentiment analysis as "bags-of-words" approaches, but they also recognize that these are the dominant form of sentiment analysis. Improvements in sentiment analysis could attempt to address context in order to disambiguate the meanings of words. For this approach to succeed, systems will almost certainly need to be trained in recognizing rhetorical tactics such as sarcasm and irony. Although training (machine learning) is possible, it is labor intensive and likely to involve domain-specific crowd-coding, which embodies human opinions, and is employed to train programs to recognize the meanings of words more specifically.

Natural language is extremely variable in terms of the emotional tone of its words, so that even one sentence might contain words with many different possible emotional impacts. For example, the sentence "I thank you with all my heart for your friendship and your confidence," which occurs in Dewey's 1948 nomination acceptance speech has an overall positive emotional tone (69, where the norm for everyday English is 50). However, along with words that are very pleasant (e.g., heart, 99; friendship, 89) the sentence includes some that are somewhat less pleasant (e.g., confidence, 42). Function words (e.g., and, 39; for, 33) are part of almost every sentence. Dewey's sentence has a standard deviation of 24.3. In absolute terms, this is greater than the standard deviation of all the words in all the speeches studied (21.8). When language is naturally variable, effect sizes associated with analyses at the level of the word will tend to be small. It is true that some single words carry extreme emotional scores, but a normal sentence has a structure that demands it contain words with very different emotional tones. Small effect sizes are neither insignificant nor meaningless. The tone of an entire speech can be changed by the inclusion of a few extreme words in it, but the speech as a whole will remain emotionally variable.

\section{RESULTS}

\section{The Overall Character of the Speeches}

Mean pleasantness for all speeches, with words as the unit of measurement, was 50.66; mean activation was 51.20 , and mean imagery 48.67. These means were compared to the norm for everyday English which was 50 with a $t$ test for one mean. All means were significantly different than $50\left(t_{146376}=11.55,21.22\right.$, and -14.08 respectively, $p<0.001)$. The speeches were pleasant, active, and abstract in comparison to everyday English. Effect sizes were weak with $d=0.03,0.08$, and 0.04 . These effect sizes should be interpreted in view of the natural variability of language discussed above. The most notable emotional characteristic of the speeches was their high activation: this is likely tied to their function, which is "pumping up the base" of supporters. The mean grade level of the speeches was 8.56, which was significantly lower than grade 12 (the last grade in secondary school; $\left.t_{37}=-13.22, p<0.001, d=1.61\right)$. The grade level of 8.56 implies that the text of the speeches is appropriate for students half-way through grade 8 . Web sites such as The Readable Blog (https://readable.com/blog/what-isthe-average-persons-reading-level/) suggest that, in order to reach a maximum audience, materials on the web should be at Grade 8 level. The average reading level of Americans is Grade 8 , so the nomination acceptance speeches were accessible to a very wide audience. The first prediction of the study (P1) was confirmed with respect to all variables. Presidential nomination acceptance speeches were pleasant, active, somewhat abstract, and linguistically simple. 


\section{Standardized Variables Plotted as a Function of Year}

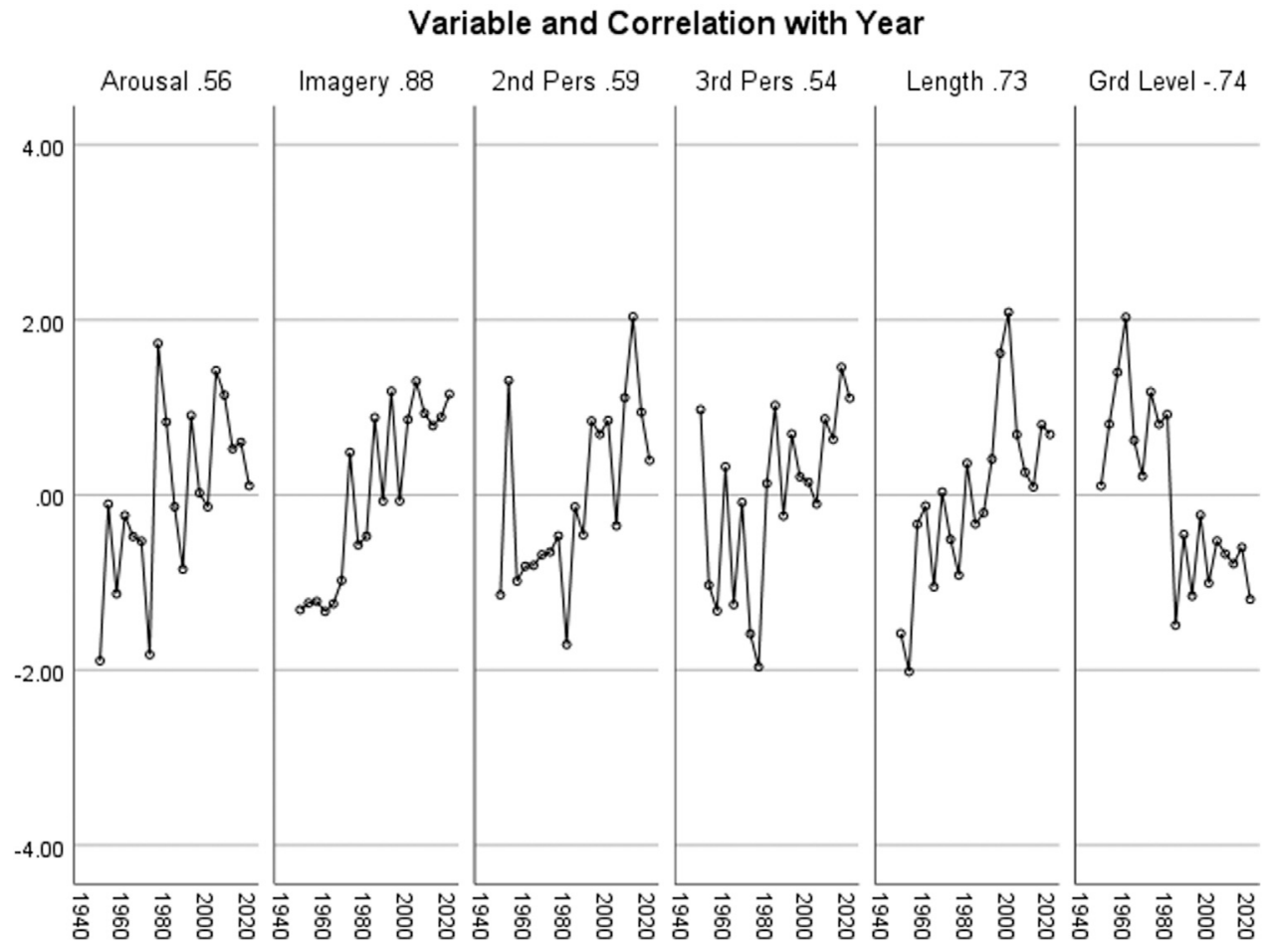

FIGURE 1 | Changes across time for six standardized variables significantly related to year.

\section{Changes in Speeches Across Time}

Mean values were calculated for each variable in each year by averaging the data for the two candidates in that year. When these mean values were correlated with year (19 observations), six significant correlations were noted (Figure 1). Arousal, imagery, use of first and second person pronouns, and length all increased significantly with year. Grade Level decreased significantly. Correlations for arousal and imagery were in accordance with predictions (P2), but pleasantness showed no change across time. The expectation of greater simplicity across time (also from P2) was supported by the negative correlation of Grade Level with year. Scores significantly related to year were standardized in order to make them comparable, and changes across time are plotted in Figure 1.

\section{Differences Among Individual Candidates' Speeches}

Means for each candidate's speech for each variable are noted in Supplementary Appendix SA. A multivariate analysis of variance was employed to compare the 38 speeches: Grade Level and length in number of words were not included in this analysis because these scores characterized entire speeches. According to a multivariate analysis of variance with word as the unit of observation and speaker as the only factor, there were significant differences among speakers for every variable (multivariate effect, $p<0.001, \eta^{2}=0.002$; univariate effects,
$2.83<\mathrm{F}_{37,146,339}<$ 9.96; $\left.p<0.001 ; 0.001<\eta^{2}<0.003\right)$. Speech lengths were compared using a goodness of fit Chi Squared statistic which indicated that some speeches were significantly longer than others $\left(\chi_{37}^{2}=21,369.07, p<0.001\right)$. Table 1 reports mean values for the two most recent speakers (Trump and Biden, 2020) along with the mean for the entire group and an estimate of two standard errors. Comparisons between any two speakers equivalent to a two-tailed $t$ test with $p$ at 0.05 can be made by subtracting one mean from the other and comparing the result to the estimate of two standard errors. When the difference exceeds the estimate, it is significant. For example, the difference between Trump and Biden for pleasantness was 0.47: this did not exceed the value of two standard errors for this variable (0.71) and was therefore not a significant difference. However, the difference between the two speakers for imagery was 1.75 , which is greater than the value of two standard errors (1.16), and therefore significant. Trump's acceptance speech was more highly imaged and Biden's was more abstract. Continuing the comparison between these two speakers, there was no difference for activation, second-person pronouns and the employment of America-words, but Biden employed relatively more first-person pronouns and Trump more third-person pronouns. Trump's speech (6,980 words) was more than twice as long as Biden's $(3,202)$. Biden's speech (Grade 5.8) was pitched at a lower Grade Level than Trump's (8.1), which was closer to the group mean Grade Level of 8.6. Comparisons within any column of Supplementary Appendix SA can be made in a similar 
TABLE 1 | Means for all speech characteristics for the two most recent presidential nomination acceptance addresses: Trump and Biden, 2020.

\begin{tabular}{|c|c|c|c|}
\hline Characteristic & Candidate Trump & Candidate Biden & $\begin{array}{c}\text { Overall } \\
\text { Mean (and } 2^{\mathrm{a}} \text { se) }\end{array}$ \\
\hline Year & 2020 & 2020 & \\
\hline Party & Republican & Democrat & \\
\hline Pleasantness & 50.42 & 50.89 & $50.66(0.71)$ \\
\hline Arousal & 51.56 & 50.85 & $51.20(0.71)$ \\
\hline Imagery & $51.05^{a}$ & 49.30 & $48.67(1.16)$ \\
\hline Use of First Person Pronouns & 0.051 & $0.060^{\mathrm{a}}$ & $0.063(0.008)$ \\
\hline Use of Second Person Pronouns & 0.013 & 0.010 & $0.012(0.004)$ \\
\hline Use of Third Person Pronouns & $0.027^{a}$ & 0.017 & $0.019(0.005)$ \\
\hline Use of America Words & 0.014 & 0.013 & $0.011(0.002)$ \\
\hline Length (in Words) & 6,980 & 3,202 & 4,157 \\
\hline Flesch-Kincaid Grade Level & 8.1 & 5.8 & 8.6 \\
\hline
\end{tabular}

Note: For pronoun use and use of America words, the data are proportions.

${ }^{a}$ This mean was significantly higher, $\mathrm{p}<.05$.

manner. Any difference between means greater than the estimate of two standard errors is statistically significant.

\section{Structure of Speeches}

Seven mixed analyses of variance with portion of the speech $\left(1^{\text {st }}\right.$ through $\left.5^{\text {th }}\right)$ as a repeated measure and party (Republican, Democrat) and status (eventual winner of presidency, eventual loser) as between-subjects variables were conducted for the outcome variables of pleasantness, activation, imagery, use of first-person, second-person, and third-person personal pronouns, and use of America-words. The unit of observation was the mean for each variable for each portion of each speech (190 observations per analysis). There were no significant differences of any kind associated with party. The eventual winner factor evinced only one significant main effect for the use of second-person pronouns $\left(F_{1,34}=6.45, p=0.016\right.$, $\left.\eta^{2}=0.16\right)$. Eventual winners employed many fewer secondperson pronouns than eventual losers ( 9 per 1,000 words as opposed to 120). There were no significant interactions involving status. There were significant main effects associated with portion of the speech for four variables: pleasantness $\left(F_{4,136}=14.57, p<0.001, \eta^{2}=0.30\right)$, the use of America-words $\left(F_{4,136}=3.30, p=0.013, \eta^{2}=0.088\right)$, and the use of first-person $\left(F_{4,136}=4.01, p=0.004, \eta^{2}=0.106\right)$ and second-person $\left(F_{4,136}=10.71, p<0.001, \eta^{2}=0.240\right)$ pronouns. In all cases where the main effect for portion was significant, the trend observed was a strong quadratic one $\left(p<0.001, \eta^{2}=\right.$ 0.679 for pleasantness; $p<0.001, \eta^{2}=0.268$ for America words; $p<0.001, \eta^{2}=0.356$ for first-person pronouns; $p<0.001$ and $\eta^{2}=0.393$ for second-person pronouns). There were no other significant effects. The strongest quadratic effect (with an overwhelming $\eta^{2}=0.68$ ) was associated with pleasantness. The U-shaped quadratic trends pictured in Figure 2 began with high scores in the first portion (higher pleasantness, more references to America, more first and second-person pronouns), dropped to lower scores for the middle portions, and rose again at the end of the speech. These changes are probably related to the fact that acceptance speeches normally open and close to the raucous acclaim and cheers of the audience.

\section{Some Post Hoc Analyses}

4 Four post hoc analyses were undertaken in order to explore differences among speeches. In the first analysis, the Mahalanobis distance measure was computed to search for multivariate outliers among the speeches in terms of the nine dependent variables: no outliers were identified as all distances had associated $p$ values $>0$.01. Next, the popularity of each candidate and their signed difference in popularity from their main competitor in July of the election year, taken from Gallup poll data, were correlated with all the dependent variables. No significant relationships were noted $(p>0.05)$. In his commentary, Mayer (2004) suggested that changes in campaign strategy might be associated with two inflection points: 1972, when the more modern convention system gelled and 1996, when the large gap between the clinching of the nomination and the convention became evident. Dummy variables were created for each of these dates, with years 1972 and later coded as 1 for the first variable and years 1996 and later coded as 1 for the second. Year and the two dummy variables were correlated with the dependent variables. Relationships for the dummy variables were often significant, but they were not stronger than relationships for year, so the dummies did not add any information to the analysis. The correlation coefficients can be viewed in Supplementary Appendix SB. In the final analysis, nomination acceptance speeches by incumbent presidents were compared to those made by other candidates. This analysis involved $t$-tests at the level of individual words $(d f>100,000$ in all cases, tests at $p<$ 0.05). Incumbents employed significantly less pleasant language $(50.42,50.78, d=0.017)$, more active language $(51.36,51.12, d=0.011)$, more highly imaged language $(49.20,48.39, d=0.022)$, fewer first-person pronouns $(0.055$, $0.061, d=0.025)$, fewer second person pronouns $(0.010,0.011, d=$ $0.011)$ and more third person pronouns $(0.019,0.017, d=0.016)$. There was no significant difference for America words. As indicated by $d$ values, the effect sizes involved were small. In comparison to incumbents, non-incumbent candidates used more pleasant and less active and imaged language, and the tended to employ more first and second person pronouns and fewer third 
person pronouns. Their speeches were therefore more personalized, and more directed at pleasing their audience.

\section{DISCUSSION}

\section{Overview of Results}

This research examined presidential nomination acceptance speeches by quantifying them in terms of nine variables: their emotional tone (pleasantness, activation), their linguistic simplicity (imagery, Grade Level), their use of personal pronouns (first, second, and third person), their use of forms of the word "America", and their length. Several predictions were made with respect to the overall character of nomination acceptance speeches. All of them were confirmed. Speeches were pleasant and active in tone, and they were also somewhat abstract but not linguistically complex. A second set of predictions addressed changes across time in acceptance speeches. All but one of the predictions in this set were also supported by the data. The speeches became more active and more concrete across time, and their language also became simpler: it had lower Grade Levels. Speeches also grew longer over time.

Exploratory analyses indicated that individual speeches differed in terms of all possible measures. A method was provided (Table 1, Supplementary Appendix SA) to allow researchers interested in making individual comparisons among speakers to do so. Further exploratory analyses addressed the structure of speeches, looking at how the measures of the study changed across the five portions of each speech (beginning, $2^{\text {nd }}$ fifth, middle, $3^{\text {rd }}$ fifth, and ending). Significant trends were identified for pleasantness, the use of America-words, and the use of first and second person pronouns. In all cases, the strongest significant trend was quadratic, pointing to a strong opening in terms of these four variables, a fall to the centre portions of the speech, and a strong closing. Speeches were all about "you", "me" and "America" in their beginnings, and their emotional tone was pleasant: platforms and issues tended to be discussed in the $2^{\text {nd }}, 3^{\text {rd }}$, and $4^{\text {th }}$ portions of the speeches, and the last portion resounded again with "you", "me", and "America", closing on a positive note (Figure 1). Additional post hoc analyses examined differences between candidates who were incumbent presidents and non-incumbents. Differences observed suggest that the language of incumbents was characterized by a more reassured and less personalized approach.

Some of the differences reported in this research-for example those associated with differences between incumbents and non-incumbents or those associated with P1-were significant but weak. This can be tracked back to the natural variability of language. Weak differences are still meaningful but they represent a small change in the overall product (the speech). The strongest effect sizes associated with the speeches as a whole were those representing their Grade Level and their activation: the base was being "pumped up" by the nominees' use of active and accessible language. The strongest effect sizes associated with changes across time were for language simplicity, i.e., increased imagery and decreased Grade Level, and for length (speeches became longer). The strongest effect size in the study of speech structure was associated with pleasantness which started high, fell in the middle of the speeches, and rose again at the end. Members of the nominees' base left the convention in an active and positive frame of mind, with the sense that the nominees had been speaking to them personally. It is notable that neither party nor the eventual status of the candidate as winner of the presidency (or not) were associated with strong differences among speeches. As a limitation, it should be noted that this research provides an overview of nomination acceptance speeches, their structure, and their differences, and that much information remains within them that could be studied at a deeper level in future research. Furthermore, changes in the ways in which nominations were made appeared at several times during the period 1948-2020, as

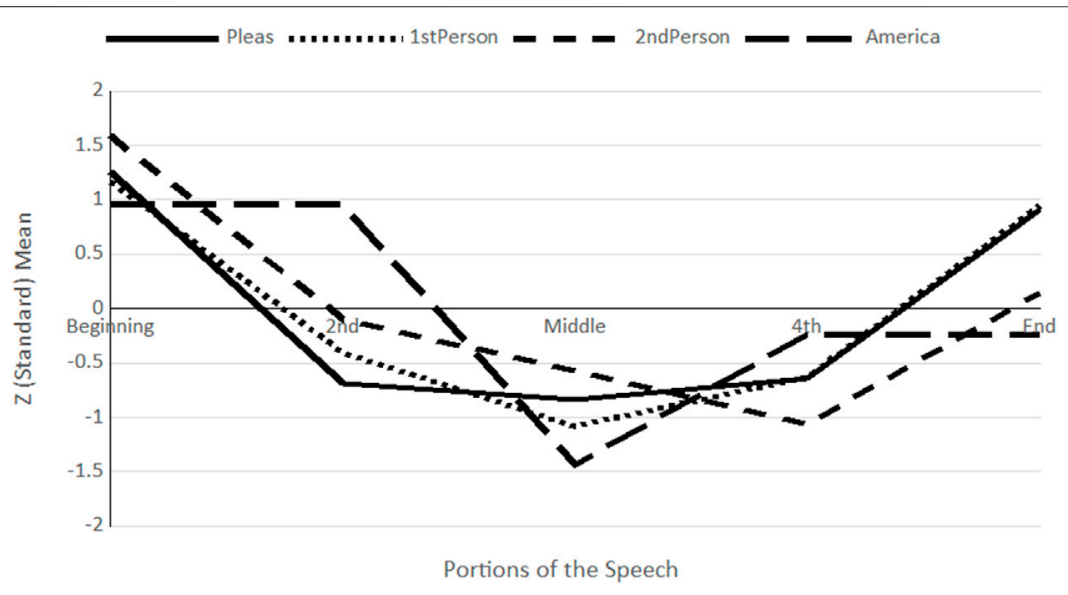

FIGURE 2 | The structure of speeches: changes across five equal portions of speeches for pleasantness and the use of first person and second person pronouns and America-words. Note: to allow for comparability, all means were plotted as standard (z) scores. 
did changes in the style and extent of media coverage. Both of these might have influenced results.

\section{Functionality of Political Speeches and Their Mass Distribution}

The predictions of this research relied on the presence of two main forces that were assumed to impact on political discourse. The first force was the functionality of such discourse and the second its mass distribution. Speeches are shaped in the way they are because their structure serves a particular function, and they are framed in more or less complex or emotional terms because it is expected that many, many Americans will engage with them, in one form or another. In their work on The Ubiquitous Presidency, Scacco and Coe (2021) brought both of these forces into focus simultaneously:

The [president's] speech will draw a massive audience, one of the biggest of the year. Those who don't encounter the speech live will see a television news recap later in the evening or read about it in tomorrow's paper ... Every word that passes the president's lips has been carefully crafted for this occasion. If he can get the message just right, the thinking goes, the public will understand his perspective and help him achieve his political aims. ...

[Moments are] produced by presidents, reported and repurposed by journalists, studied by scholars, witnessed and talked about by citizens. In combination, these moments form a mythology that lives on in books and on websites, in high school and college classes, in popular portrayals of the presidency, and in the public imagination. (p. 1).

\section{REFERENCES}

Benoit, W. L. (2014). A Functional Analysis of 2008 and 2012 Presidential Nomination Acceptance Speeches. Speaker. Gavel. 51, 50-59.

Benoit, W. L. (1999). Acclaiming, Attacking, and Defending in Presidential Nominating Acceptance Addresses, 1960-1996. Q. J. Speech. 85, 247-267. doi:10.1080/00335639909384260

Benoit, W. L., Blaney, J. R., and Pier, P, M. (1998). Campaign '96: A Functional Analysis of Acclaiming, Attacking, and Defending. Westport, Connecticut: Praeger.

Benoit, W. L., Stein, K. A., and Hansen, G. J. (2004). How Newspapers Cover Presidential Nomination Acceptance Addresses. Newspaper Res. J. 25, 83-89. doi:10.1177/073953290402500308

Bull, P., and Fetzer, A. (2006). Who Are We and Who Are You? the Strategic Use of Forms of Address in Political Interviews. Text Talk. 26, 3-37. doi:10.1515/ text.2006.002

Carlton, W. G. (1957). The Revolution in the Presidential Nominating Convention. Pol. Sci. Quart. 72, 224-240. doi:10.2307/2145774

Deason, G., and Gonzales, M. H. (2012). Moral Politics in the 2008 Presidential Convention Acceptance Speeches. Basic Appl. Soc. Psychol. 34, 254-268. doi:10.1080/01973533.2012.674450

Marre, Q., Huet, N., and Labeye, E. (2021). Embodied Mental Imagery Improves Memory. Q. J. Exp. Psychol. 1, 174702182110092. doi:10.1177/17470218211009227

Mayer, W. G. (2004). From the End of the Nomination Contest to the Start of the National Conventions: Preliminary Thoughts on a New Period in Presidential
The authors go on to make the point that the presidency has morphed in recent years, and has gone from being a mainly rhetorical presidency to being a ubiquitous one, where news is managed in much more complex ways than it had been in the past. One might consider nomination acceptance speeches to be less relevant and impactful than, for example, inaugural addresses or messages on the State of the Union. They are, however, part of the total package of carefully managed political language that focuses relentlessly on its goal of access to power. The names of speakers are identifiers: it is suggested that each of them represents his party's drive for success in any given year, as well as representing themselves. The speaker does impact the speech-Reagan and Trump's speeches, for example, echo their distinctive uses of language-however this is accomplished within a solid understanding of the purpose of the speech (to lead to an electoral win) and the nature of its audience (a very wide one).

\section{DATA AVAILABILITY STATEMENT}

The raw data supporting the conclusion of this article will be made available by the authors, without undue reservation.

\section{AUTHOR CONTRIBUTIONS}

CW downloaded and analysed the data. She also wrote the article.

\section{SUPPLEMENTARY MATERIAL}

The Supplementary Material for this article can be found online at: https://www.frontiersin.org/articles/10.3389/fcomm.2021.729751/ full\#supplementary-material

Campaign Politics. The Forum. 2 (2), 0000102202154088841032. doi:10.2202/ 1540-8884.1032

Miller, N. L., and Stiles, W. B. (1986). Verbal Familiarity in American Presidential Nomination Acceptance Speeches and Inaugural Addresses (1920-1981). Soc. Psychol. Q. 49, 72-81. doi:10.2307/2786858

Putri, N. A., and Kurniawan, E. (2015). Person Deixis in USA Presidential Camp Aign Speeches. English Review. J. English Educ. 3, 190-200.

Rudkowsky, E., Haselmayer, M., Wastian, M., Jenny, M., Emrich, Š., and Sedlmair, M. (2018). More Than Bags of Words: Sentiment Analysis with Word Embeddings. Commun. Methods Measures. 12, 140-157. doi:10.1080/ 19312458.2018.1455817

Savoy, J. (2010). Lexical Analysis of US Political Speeches. J. Quantitative Linguistics. 17, 123-141. doi:10.1080/09296171003643205

Scacco, J. M., and Coe, K. (2021). The Ubiquitous Presidency: Presidential Communication and Digital Democracy in Tumultuous Times. Oxford: Oxford University Press.

Sigelman, L. (2002). Two Reagans? Genre Imperatives, Ghostwriters, and Presidential Personality Profiling. Polit. Psychol. 23, 839-851. doi:10.1111/ 0162-895x.00310

Sigelman, L., and Whissell, C. (2002). "The Great Communicator" and "The Great Talker" on the Radio: Projecting Presidential Personas. Presidential Stud. Q. 32, 137-146. doi:10.1111/j.17415705.2002.tb00017.x

Stockmeyer, N. O. (2009). Using Microsoft Word's Readability Program. Mich. Bar J. $88,46-47$ 
Valley, D. B. (1972). A History and Analysis of Democratic Presidential Nomination Acceptance Speeches to 1968. Urbana-Champaign: University of Illinois. $\mathrm{PhD}$ Dissertation. Available at: https://www.proquest.com/docview/302691355?pqorigsite $=$ gscholar\&fromopenview $=$ true.

Vecchi, T. (2019). Imagery and Imagination in Psychological Science. IMGJournal 1, 314-317. Available at: http://www.img-network.it/wp-content/uploads/ 2020/01/IMGjournal-ISSUE01-a24-Vecchi.pdf.

Vertommen, B. (2013). The Strategic Value of Pronominal Choice. Prag 23, 361-383. doi:10.1075/prag.23.2.07ver

Waldeman, M. (2010). My Fellow Americans: The Most Important Speeches of America's Presidents from George Washington to Barack Obama. Naperville, Illinois: Sourcebooks.

Whissell, C., and Sigelman, L. (2001). The Times and the Man as Predictors of Emotion and Style in the Inaugural Addresses of U.S. Presidents. Comput. Humanities. 35, 255-272. doi:10.1023/A:1017569003556

Whissell, C. (2012). The Emotionality and Complexity of Public Political Language in Canada's Question Period. Ells 2, 68-76. doi:10.5539/ells.v2n4p68

Whissell, C. (2009). Using the Revised Dictionary of Affect in Language to Quantify the Emotional Undertones of Samples of Natural Language. Psychol. Rep. 105, 509-521. doi:10.2466/pr0.105.2.509-521
Young, L., and Soroka, S. (2012). Affective News: the Automated Coding of Sentiment in Political Texts. Politic. Commun. 29, 205-231. doi:10.1080/ 10584609.2012.671234

Conflict of Interest: The author declares that the research was conducted in the absence of any commercial or financial relationships that could be construed as a potential conflict of interest.

Publisher's Note: All claims expressed in this article are solely those of the authors and do not necessarily represent those of their affiliated organizations, or those of the publisher, the editors and the reviewers. Any product that may be evaluated in this article, or claim that may be made by its manufacturer, is not guaranteed or endorsed by the publisher.

Copyright $(2021$ Whissell. This is an open-access article distributed under the terms of the Creative Commons Attribution License (CC BY). The use, distribution or reproduction in other forums is permitted, provided the original author(s) and the copyright owner(s) are credited and that the original publication in this journal is cited, in accordance with accepted academic practice. No use, distribution or reproduction is permitted which does not comply with these terms. 